\title{
Crescimento e nutrição de mudas de clones de eucalipto inoculadas com fungos micorrízicos ${ }^{1}$
}

\author{
Francisco de Sousa Lima ${ }^{2}$, Carla da Silva Sousa ${ }^{2}$
}

\begin{abstract}
Growth and nutrition of eucalyptus clones seedlings inoculated with mycorrhizal fungi

Eucalyptus is one of the most planted forest species, in Brazil, due to its rapid growth and high economic yield. Arbuscular mycorrhizal fungi improve the seedlings nutritional and phytosanitary status, besides increasing their resistance to biotic and abiotic stress. This study aimed to evaluate the effect of inoculation with arbuscular mycorrhizal fungi species on the growth and nutrition of different eucalyptus clones seedlings. The experiment was conducted under greenhouse conditions, in a randomized blocks design and a $5 \times 5$ factorial scheme (five fungal species and five eucalyptus clones), with five replications. In general, the mycorrhizal symbiosis significantly increased the growth and nutrition of eucalyptus seedlings, when compared to the non-inoculated seedlings. The most efficient interaction occured between the 2361 clone and the Entrophospora infrequens fungus, with increases of $107.3 \%$ and $120.6 \%$, for the shoot and root dry biomass yield, and $107.7 \%, 94.1 \%$ and $103.3 \%$, respectively for the accumulation of $\mathrm{N}, \mathrm{P}$ and $\mathrm{K}$ in the seedlings shoots. All the fungal species studied showed a high absolute compatibility index with eucalyptus clones. The Glomus manihots and E. infrequens fungi presented a higher functional compatibility index with the clones tested. The 5204 clone showed $75 \%$ of compatibility with the fungi evaluated.
\end{abstract}

KEY-WORDS: Eucaliptus grandis; Eucaliptus urophylla; mycorrhizal association.

\section{INTRODUÇÃO}

Como outras espécies vegetais exóticas, a exemplo do café, cana-de-açúcar e soja, o eucalipto encontrou, no solo e clima brasileiros, condições ideais para a produção em grande escala, de tal modo que, praticamente, todas as grandes indústrias de celulose e madeira do mundo estão presentes no Brasil (Lopes 2008).

O êxito na formação de florestas de alta produção depende, em grande parte, da qualidade das

\section{RESUMO}

Uma das essências florestais mais plantadas no Brasil é o eucalipto, em razão de seu rápido crescimento e elevado rendimento econômico. Fungos micorrízicos arbusculares proporcionam melhoria nutricional e fitossanitária às mudas, além de maior resistência a fatores bióticos e abióticos. Este trabalho objetivou avaliar o efeito da inoculação com espécies de fungos micorrízicos arbusculares, no crescimento e nutrição de mudas de diferentes clones de eucalipto. Foi conduzido experimento em condições de casa-de-vegetação, em delineamento de blocos casualizados e esquema fatorial $5 \times 5$ (cinco espécies fúngicas e cinco clones de eucalipto), com cinco repetições. De modo geral, a simbiose micorrízica proporcionou incrementos significativos no crescimento e na nutrição das mudas de eucalipto, em comparação às mudas não inoculadas. A interação mais eficiente foi entre o clone 2361 e o fungo Entrophospora infrequens, na qual foram registrados aumentos de $107,3 \%$ e $120,6 \%$, na produção de biomassa seca na parte aérea e nas raízes, e de $107,7 \%, 94,1 \%$ e $103,3 \%$, respectivamente para o acúmulo de $\mathrm{N}, \mathrm{P}$ e K, na parte aérea das mudas. Todas as espécies fúngicas apresentaram alto índice de compatibilidade absoluta com os clones de eucalipto. Os fungos Glomus manihots e E. infrequens apresentaram maior índice de compatibilidade funcional com os clones testados. O clone 5204 apresentou compatibilidade com $75 \%$ dos fungos avaliados.

PALAVRAS-CHAVE: Eucaliptus grandis; Eucaliptus urophylla; associação micorrízica.

mudas plantadas, que, além de terem que resistir às condições adversas encontradas no campo, após o transplantio, deverão sobreviver e, por fim, produzir árvores com crescimento volumétrico economicamente desejável (Gomes et al. 1991).

Dentre as diversas relações simbióticas existentes entre plantas e micro-organismos, destacam-se as micorrizas. As micorrizas arbusculares são associações entre plantas e fungos do solo do filo Glomeromycota (Schüßler et al. 2001). O benefício da associação para a planta surge do aumento da su- 
perfície de absorção de nutrientes pelas hifas fúngicas e, em troca, o fungo é subsidiado por carboidratos fotoassimilados (Herrman et al. 2004).

A exploração das associações micorrízicas, por meio da inoculação com fungos micorrízicos arbusculares (FMA), e a utilização de substratos adequados proporcionam a produção de mudas com melhor qualidade nutricional e fitossanitária, devido ao aumento da capacidade de absorção de nutrientes das raízes (Machineski et al. 2009, Sousa et al. 2010) e maior tolerância a patógenos radiculares (Sousa et al. 2010) e estresses abióticos (Moratelli et al. 2007), promovidos pela colonização radicular e pelo desenvolvimento das hifas externas dos FMA (Cavalcante et al. 2001). Por esta razão, durante o processo de produção de mudas micorrizadas, diferentes espécies de fungos micorrízicos arbusculares devem ser testadas em uma mesma planta, sob as mesmas condições ambientais, para selecionar espécies fúngicas eficientes, quanto à capacidade de promover melhor crescimento vegetativo, melhoria nutricional e fitossanitária ao seu hospedeiro (Saggin Júnior \& Siqueira 1995).

Estudos têm demonstrado que o eucalipto apresenta grande susceptibilidade à formação de micorriza arbuscular (Araújo et al. 2004, Schiavo et al. 2010a, Campos et al. 2011). Alguns autores também já constataram, em plantios de eucalipto, que a idade da planta tem influência sobre o tipo de associação micorrízica, de modo que, inicialmente, há colonização por fungos micorrízicos arbusculares substituída, progressivamente, por associações de fungos ectomicorrízicos (Mello et al. 2006). Entretanto, pouco se sabe sobre a influência da espécie de eucalipto sobre o estabelecimento da simbiose micorrízica, ou seja, quais espécies fúngicas possuem maior grau de compatibilidade com diferentes clones desta espécie florestal, e que seriam mais promissoras em programas de produção de mudas de eucalipto micorrizadas.

Embora a associação micorrízica seja considerada não específica, quanto à relação fungo-planta, evidências de comportamento específico têm aumentado (Bever 2002). Tais diferenças na relação fungo-planta são, possivelmente, reflexos das complexas interações que se expressam como efeitos específicos de base bioquímica, genética e fisiológica (Pouyu-Rojas et al. 2006).

O conhecimento da eficiência simbiótica de espécies de fungos micorrízicos arbusculares, em diferentes clones de eucalipto, serve como suporte para otimizar o processo de produção de mudas de eucalipto micorrizadas, visando ao melhor desenvolvimento dos clones, na fase de viveiro, e, consequentemente, melhor estabelecimento destas mudas em campo, com vistas a reduzir as perdas, durante estas etapas, e os custos com a aplicação de fertilizantes químicos e defensivos agrícolas.

Nesse sentido, este trabalho objetivou avaliar a eficiência de espécies de fungos micorrízicos arbusculares na promoção do crescimento e melhoria nutricional de mudas de diferentes clones de eucalipto.

\section{MATERIAL E MÉTODOS}

O experimento foi conduzido em condições de casa-de-vegetação, na Universidade Federal do Recôncavo da Bahia (UFRB), Campus Cruz das Almas (BA), de abril a julho de 2011, em delineamento de blocos casualizados e esquema fatorial $5 \times 5$, com quatro espécies de fungos micorrízicos arbusculares (Glomus etunicatum, Glomus manihots, Acaulospora sp. e Entrophosphora infrequens) e um tratamento controle (sem inoculação micorrízica) e cinco clones de eucalipto, com cinco repetições.

Inicialmente, mudas de clones híbridos das espécies Eucaliptus grandis x Eucaliptus urophylla 1250, 0321, 2361, 5204 e 5341 foram produzidas por propagação vegetativa, por meio de estaquia, no viveiro da Copener Florestal Ltda., em tubetes contendo $100 \mathrm{~cm}^{3}$ de uma mistura de fibra de coco e substrato comercial, na proporção 1:1 (v/v). Subamostras do substrato foram coletadas, sendo realizada sua caracterização química (Tabela 1).

Após o período de enraizamento, que ocorreu entre 5 e 10 dias, as mudas foram transplantadas para tubetes contendo $230 \mathrm{~cm}^{3}$ do substrato. No momento do transplantio, cada muda foi inoculada, colocando-se, junto às raízes, com o auxílio de uma pipeta Pasteur, suspensão aquosa contendo 200 esporos da espécie fúngica. Logo após, $10 \mathrm{~mL}$ de uma suspensão obtida do solo inóculo diluído em água e filtrado em peneira de $50 \mu \mathrm{m}$, portanto, isenta de propágulos de FMA, foram adicionados a todos os vasos, visando a equilibrar a população microbiana do solo. As mudas foram mantidas em condições de viveiro (50\% de sombra), sendo irrigadas com água destilada, conforme a necessidade.

Para a obtenção de inóculo dos fungos micorrízicos arbusculares, sementes de Brachiaria decumbens foram desinfestadas com solução aquosa 
Tabela 1. Caracterização química do substrato utilizado no experimento (Cruz das Almas, BA, 2011).

\begin{tabular}{lcr}
\hline \multicolumn{1}{c}{ Característica } & Unidade & Conteúdo \\
\hline $\mathrm{pH}$ & $\mathrm{CaCl}_{2} 0,01 \mathrm{M}$ & 5,3 \\
Matéria orgânica total & $\mathrm{g} \mathrm{kg}^{-1}$ & 123,4 \\
Carbono orgânico & $\mathrm{g} \mathrm{kg}^{-1}$ & 71,6 \\
$\mathrm{~N}$ total & $\mathrm{g} \mathrm{kg}^{-1}$ & 3,4 \\
$\mathrm{P}$ total & $\mathrm{g} \mathrm{kg}^{-1}$ & 8,4 \\
$\mathrm{~K}^{+}$ & $\mathrm{g} \mathrm{kg}^{-1}$ & 9,5 \\
$\mathrm{Ca}^{+2}$ & $\mathrm{~g} \mathrm{~kg}^{-1}$ & 13,8 \\
$\mathrm{Mg}^{+2}$ & $\mathrm{~g} \mathrm{~kg}^{-1}$ & 17,5 \\
$\mathrm{~S}$ & $\mathrm{~g} \mathrm{~kg}^{-1}$ & 3,6 \\
$\mathrm{Relação} \mathrm{C/N}$ & - & $24 / 1$ \\
$\mathrm{Cu}$ & $\mathrm{mg} \mathrm{kg}^{-1}$ & 10,0 \\
$\mathrm{Mn}$ & $\mathrm{mg} \mathrm{kg}^{-1}$ & 134,0 \\
$\mathrm{Zn}^{++}$ & $\mathrm{mg} \mathrm{kg}^{-1}$ & 58,0 \\
$\mathrm{Fe}^{+++}$ & $\mathrm{mg} \mathrm{kg}^{-1}$ & $16.696,0$ \\
$\mathrm{~B}^{++}$ & $\mathrm{mg} \mathrm{kg}^{-1}$ & 3,0 \\
$\mathrm{Na}^{++}$ & $\mathrm{mg} \mathrm{kg}^{-1}$ & $1.121,0$ \\
\hline
\end{tabular}

de $1 \%$ de hipoclorito de sódio e três lavagens em água corrente e, em seguida, foram semeadas em areia esterilizada. Uma semana após a germinação, as plântulas foram transplantadas para vasos com capacidade para $3 \mathrm{~kg}$, contendo solo e areia, na proporção de $3: 1(\mathrm{v} / \mathrm{v})$, previamente esterilizados em autoclave, a $120^{\circ} \mathrm{C}$, durante uma hora e meia, em três dias alternados.

Na fase de transplantio, cada plântula foi inoculada, colocando-se, junto às raízes, com o auxílio de uma pipeta Pasteur, suspensão aquosa contendo, aproximadamente, 200 esporos da espécie fúngica por vaso. Os vasos foram mantidos em casa-de-vegetação por 120 dias, sob irrigações diárias, com água destilada.

Após 90 dias, foi medida a altura das mudas (distância entre o nível do solo e a inserção do broto terminal da haste principal), com o auxílio de uma régua milimetrada, e do diâmetro do caule $(5 \mathrm{~cm}$ acima do colo da planta), utilizando-se paquímetro digital. As mudas foram coletadas, separando-se a parte aérea das raízes, que, em seguida, foram acondicionadas em saco de papel e transportadas para estufa de secagem com ventilação forçada a $65^{\circ} \mathrm{C}$, por 3 dias, para determinação da biomassa seca da parte aérea e radicular. O material vegetal referente à parte aérea das plantas, após seco, foi moído em moinho tipo Willey e mineralizado por meio de digestão com ácido sulfúrico e peróxido de hidrogênio (Thomas et al. 1967). Nos extratos, os teores de $\mathrm{N}$ foram determinados pelo método de Kjeldahl, os de P por colorimetria e os de K por fotometria de chama.

Subamostras de raízes finas ( $>2 \mathrm{~mm}$ ) frescas das mudas foram coletadas, para determinação da colonização micorrízica. Seguindo-se a metodologia de coloração proposta por Koske \& Gemma (1989), as raízes foram clarificadas com solução de $\mathrm{KOH}$ (10\%), por 24 horas, em temperatura ambiente, seguida de imersão em solução de $\mathrm{H}_{2} \mathrm{O}_{2}(10 \%)$, por 45 minutos. Após o procedimento de clarificação, as raízes foram acidificadas em solução de $\mathrm{HCl}$ (1\%), durante 3 minutos, seguida de imersão em solução de Azul de Trypan (0,05\%), na qual permaneceram por 24 horas. Após a coloração de cada repetição, foram montadas 10 lâminas, cada uma delas contendo 100 segmentos $( \pm 1 \mathrm{~cm})$ de raízes coloridas, para visualização de estruturas fúngicas (arbúsculos, vesículas e hifas), com o auxílio de um microscópio estereoscópico (40x).

Foi realizado o cálculo da taxa de incremento de biomassa seca promovida pela inoculação, utilizando-se a fórmula I $(\%)=100[(\mathrm{X}-\mathrm{Y}) / \mathrm{Y}]$, em que $\mathrm{I}=$ incremento de biomassa seca, $\mathrm{X}=$ planta micorrizada e $\mathrm{Y}=$ planta controle. Para melhor entendimento dos efeitos e comparação das diferentes espécies de FMA entre os clones de eucalipto, foi calculado o índice de compatibilidade absoluta, por meio da fórmula ICA $(\%)=[$ (número de clones colonizados/número de clones estudados) x 100]. Foram calculados, também, o índice de compatibilidade funcional $\{\mathrm{ICF}(\%)=[$ (número de clones com colonização $\geq 20 \%$ / número de clones estudados) $x$ 100]\} e o índice de susceptibilidade micorrízica da planta $\{(\mathrm{ICp})=[$ (número de fungos com os quais a planta apresentou $\mathrm{CM} \geq \mathrm{média/} \mathrm{número} \mathrm{de} \mathrm{tratamen-}$ tos fúngicos) $\mathrm{x} 100]\}$.

Os resultados obtidos foram submetidos à analise de variância e teste de Scott-Knott, a 5\%, para a comparação das médias, utilizando-se o programa estatístico Sisvar. Os dados referentes à percentagem de colonização micorrízica foram transformados em $\operatorname{arcsen} \sqrt{ } x / 100$.

\section{RESULTADOS E DISCUSSÃO}

Não foi observado efeito significativo da inoculação com os fungos micorrízicos arbusculares (FMA) na altura dos clones 1250, 0321, 2361 e 5341 (Tabela 2). Todas as espécies de FMA promoveram 
Tabela 2. Altura e diâmetro de plantas, biomassa seca da parte aérea e raízes de mudas de eucalipto inoculadas com fungos micorrízicos arbusculares (Cruz das Almas, BA, 2011).

\begin{tabular}{|c|c|c|c|c|c|}
\hline \multirow{2}{*}{ Espécie fúngica } & \multicolumn{5}{|c|}{ Clones de Eucaliptus grandis x Eucaliptus urophylla } \\
\hline & 1250 & 0321 & 2361 & 5204 & 5341 \\
\hline & \multicolumn{5}{|c|}{ Altura das plantas $(\mathrm{cm})$} \\
\hline Glomus etunicatum & $26,6 \mathrm{bB}$ & $28,7 \mathrm{aB}$ & $29,1 \mathrm{aB}$ & $24,6 \mathrm{aB}$ & $32,2 \mathrm{aA}$ \\
\hline Glomus manihots & $31,4 \mathrm{aA}$ & $26,9 \mathrm{aA}$ & $29,2 \mathrm{aA}$ & $28,1 \mathrm{aA}$ & $28,0 \mathrm{aA}$ \\
\hline Acaulospora sp. & $31,8 \mathrm{aA}$ & $26,5 \mathrm{aB}$ & $29,2 \mathrm{aA}$ & $25,7 \mathrm{aB}$ & $32,2 \mathrm{aA}$ \\
\hline Entrophosphora infrequens & $33,2 \mathrm{aA}$ & $29,0 \mathrm{aA}$ & $29,7 \mathrm{aA}$ & $24,0 \mathrm{aB}$ & $32,2 \mathrm{aA}$ \\
\hline Controle & $31,7 \mathrm{aA}$ & $24,1 \mathrm{aB}$ & $25,2 \mathrm{aB}$ & $19,2 \mathrm{bC}$ & $31,0 \mathrm{aA}$ \\
\hline \multirow[t]{2}{*}{ CV(\%) } & \multicolumn{5}{|c|}{9,54} \\
\hline & \multicolumn{5}{|c|}{ Diâmetro do caule $(\mathrm{mm})$} \\
\hline Glomus etunicatum & $3,87 \mathrm{aA}$ & $3,67 \mathrm{aA}$ & $3,52 \mathrm{aA}$ & $2,95 \mathrm{aB}$ & $3,45 \mathrm{aA}$ \\
\hline Glomus manihots & $3,02 \mathrm{bA}$ & $3,45 \mathrm{bA}$ & $3,40 \mathrm{aA}$ & $2,85 \mathrm{aA}$ & $3,30 \mathrm{aA}$ \\
\hline Acaulospora sp. & $3,22 \mathrm{bA}$ & $3,27 \mathrm{bA}$ & $3,65 \mathrm{aA}$ & $2,97 \mathrm{aA}$ & $3,57 \mathrm{aA}$ \\
\hline Entrophosphora infrequens & $3,27 \mathrm{bA}$ & $3,92 \mathrm{aA}$ & $3,65 \mathrm{aA}$ & $3,25 \mathrm{aA}$ & 3,35 aA \\
\hline Controle & $3,07 \mathrm{bA}$ & $3,02 \mathrm{bA}$ & $3,20 \mathrm{aA}$ & $3,07 \mathrm{aA}$ & 3,37 aA \\
\hline \multirow[t]{2}{*}{$\mathrm{CV}(\%)$} & \multicolumn{5}{|c|}{12,29} \\
\hline & \multicolumn{5}{|c|}{ Biomassa seca da parte aérea (g) } \\
\hline Glomus etunicatum & $2,51 \mathrm{aA}$ & $2,74 \mathrm{aA}$ & $1,92 \mathrm{cC}$ & $1,44 \mathrm{aD}$ & $2,27 \mathrm{aB}$ \\
\hline Glomus manihots & $2,35 \mathrm{bA}$ & $2,37 \mathrm{bA}$ & $2,11 \mathrm{cA}$ & $1,39 \mathrm{aB}$ & $2,41 \mathrm{aA}$ \\
\hline Acaulospora sp. & $2,69 \mathrm{aA}$ & $2,20 \mathrm{bB}$ & $2,40 \mathrm{bB}$ & $1,41 \mathrm{aC}$ & $2,63 \mathrm{aA}$ \\
\hline Entrophosphora infrequens & $2,22 \mathrm{bB}$ & $1,68 \mathrm{cC}$ & $2,82 \mathrm{aA}$ & $1,52 \mathrm{aC}$ & $1,70 \mathrm{bC}$ \\
\hline Controle & $1,72 \mathrm{cA}$ & $1,68 \mathrm{cA}$ & $1,36 \mathrm{~dB}$ & $0,77 \mathrm{bC}$ & $1,70 \mathrm{bA}$ \\
\hline \multirow[t]{2}{*}{$\mathrm{CV}(\%)$} & \multicolumn{5}{|c|}{10,95} \\
\hline & \multicolumn{5}{|c|}{ Biomassa seca das raízes ( $g$ ) } \\
\hline Glomus etunicatum & $0,39 \mathrm{aB}$ & $0,74 \mathrm{aA}$ & $0,48 \mathrm{bB}$ & $0,28 \mathrm{aC}$ & $0,67 \mathrm{aA}$ \\
\hline Glomus manihots & $0,32 \mathrm{aB}$ & $0,49 \mathrm{bA}$ & $0,49 \mathrm{bA}$ & $0,29 \mathrm{aB}$ & $0,59 \mathrm{bA}$ \\
\hline Acaulospora sp. & $0,39 \mathrm{aB}$ & $0,72 \mathrm{aA}$ & $0,66 \mathrm{aA}$ & $0,29 \mathrm{aB}$ & $0,79 \mathrm{aA}$ \\
\hline Entrophosphora infrequens & $0,29 \mathrm{aC}$ & $0,47 \mathrm{bB}$ & $0,75 \mathrm{aA}$ & $0,30 \mathrm{aC}$ & $0,53 \mathrm{bB}$ \\
\hline Controle & $0,31 \mathrm{aC}$ & $0,58 \mathrm{bB}$ & $0,34 \mathrm{bC}$ & $0,26 \mathrm{aC}$ & $0,73 \mathrm{aA}$ \\
\hline $\mathrm{CV}(\%)$ & \multicolumn{5}{|c|}{17,39} \\
\hline
\end{tabular}

Médias seguidas da mesma letra não diferem, estatisticamente, pelo teste de Scott-Knott, a 5\%. Letras minúsculas comparam, na coluna, o efeito da inoculação das diferentes espécies de FMA, para cada clone de eucalipto. Letras maiúsculas comparam, na linha, o efeito de cada espécie de FMA, entre os diferentes clones de eucalipto.

aumento na altura das mudas do clone 5204, sendo observados incrementos que variaram entre $25 \%$ e $46,3 \%$, em comparação às mudas não inoculadas.

Analisando-se o efeito de cada espécie fúngica, entre os clones de eucalipto, observou-se que o clone 5341 foi o que melhor respondeu à inoculação com o fungo G. etunicatum. Os clones não diferiram, estatisticamente, entre si, com relação à altura, quando inoculados com o fungo G. manihots. A inoculação com o fungo Acaulospora sp. foi eficiente em promover aumento na altura dos clones 1250, 2361 e 5341. Com exceção do 5204, os demais clones apresentaram aumento na altura, quando inoculados com o fungo $E$. infrequens.

No tratamento controle, no qual não houve inoculação com os FMA, observou-se maiores valores referentes à altura, nas mudas dos clones 1250 e 5341, seguidos dos clones 0321 e 2361.
Shiavo et al. (2010a) verificaram que a inoculação de mudas de Eucalyptus camaldulensis com as espécies fúngicas Glomus macrocarpum, Glomus etunicatum e Entrophospora colombiana promoveu incrementos de até 40,2\%, na altura das plantas. Estudos recentes demonstraram que a inoculação micorrízica também promoveu aumento na altura de mudas de diversas espécies florestais, dentre elas o cedro (Rocha et al. 2006), angico (Sugai et al. 2011) e peroba (Machineski et al. 2009).

Somente a inoculação com o fungo G. etunicatum promoveu incremento significativo $(26,1 \%)$ no diâmetro do caule das mudas do clone 1250. As demais espécies fúngicas não diferiram, estatisticamente, do tratamento controle. Para o clone 0321, os fungos E. infrequens e G. etunicatum promoveram incrementos de $29,8 \%$ e $21,5 \%$, respectivamente, no diâmetro do caule, em comparação às mudas não inoculadas. 
Não houve efeito significativo da inoculação com as espécies de FMA no diâmetro do caule dos clones 2361,5204 e 5341 . Os clones avaliados não diferiram, estatisticamente, entre si, com relação ao diâmetro do caule, quando inoculados com os fungos G. manihots, Acaulospora sp. e E. infrequens.

A inoculação com as espécies fúngicas Acaulospora sp. e G. etunicatum promoveu incrementos de $56,4 \%$ e $45,9 \%$, respectivamente, na produção de biomassa seca da parte aérea das mudas do clone 1250. No clone 0321, com exceção do fungo E. infrequens, que não diferiu, estatisticamente, do tratamento controle, a inoculação das demais espécies de FMA proporcionou incremento de até $63,1 \%$, na produção de biomassa seca da parte aérea. Mudas do clone 2361 apresentaram aumento que variou de $41,1 \%$ a $107,3 \%$, na produção de biomassa da parte aérea, quando inoculadas com os FMA. No clone 5204, todas as espécies de FMA favoreceram a produção de biomassa na parte aérea, sendo observado aumento de até $97,45 \%$, promovido pelo fungo $E$. infrequens. Nas mudas do clone 5341, observou-se que, com exceção do fungo $E$. infrequens, que não diferiu, significativamente, do tratamento controle, a inoculação com as demais espécies de FMA proporcionou aumento na produção de biomassa seca, na parte aérea das plantas.

Mudas de angico cultivadas em solo antropizado, quando submetidas à inoculação conjunta das espécies fúngicas G. etunicatum e Gigaspora margarita, apresentaram aumento na produção de biomassa seca, na parte aérea, de até 66,7\% (Sugai et al. 2011). Schiavo et al. (2010a) verificaram que a colonização de mudas de Acacia mangium e Sesbania virgata, pelas espécies G. macrocarpum, G. etunicatum e E. colombiana, promoveu aumento na produção de biomassa seca, na parte aérea, de $46,9 \%$ e $51,8 \%$, respectivamente.

Analisando-se o efeito de cada espécie fúngica, entre os diferentes clones de eucalipto, observou-se que as mudas dos clones 1250 e 0321 foram as que melhor responderam à inoculação do fungo G. etunicatum, apresentando maior produção de biomassa seca, na parte aérea, em comparação às mudas dos demais clones avaliados. $\mathrm{O}$ clone 5204 foi inferior aos demais, quanto à produção de biomassa, quando as mudas foram inoculadas pelo fungo G. manihots. As mudas do clone 2361, quando inoculadas com o fungo E. infrequens, apresentaram maior produção de biomassa seca, na parte aérea, que as mudas dos demais clones.
Não foi observado efeito significativo da inoculação com as espécies de FMA sobre a produção de biomassa seca, nas raízes dos clones 1250, 5204 e 5341. Mudas do clone 0321 apresentaram aumento na produção de biomassa seca radicular, quando inoculadas pelos fungos G. etunicatum $(27,6 \%)$ e Acaulospora sp (24,1\%). Os fungos Acaulospora sp. e E. infrequens promoveram incrementos de $94,1 \% \mathrm{e}$ $120,6 \%$, respectivamente, na produção de biomassa, nas raízes do clone 2361 .

Mudas do clone 2361 destacaram-se, em relação às mudas dos demais clones, com relação à produção de biomassa seca das raízes, quando inoculadas pelo fungo E. infrequens. Mudas de peroba rosa inoculadas com G. margarita apresentaram aumento de até $400 \%$, na produção de biomassa, na parte aérea e nas raízes (Machineski et al. 2009). Mudas de embaúba submetidas à inoculação com FMA apresentaram maior produção de raízes, quando comparadas às mudas não inoculadas (Carneiro et al. 2004).

A inoculação com as espécies de FMA não exerceu efeito significativo sobre o conteúdo foliar de N, nos clones 1250 e 0321 (Tabela 3). Contudo, verificaram-se incrementos de $107,7 \%$ e $100 \%$, no acúmulo de $\mathrm{N}$, na parte aérea dos clones 2361 e 5204, respectivamente, promovidos pelo fungo E. infrequens. No clone 5341, a inoculação com as espécies fúngicas G. etunicatum e Acaulospora sp. promoveu incremento de $40 \%$ e $60 \%$, respectivamente, no conteúdo de $\mathrm{N}$, em comparação às mudas não inoculadas.

Os clones de eucalipto 1250, 0321 e 5341 foram os mais beneficiados pela inoculação com os fungos G. etunicatum e G. manihots. Mudas do clone 5341 foram as que melhor responderam à inoculação do fungo Acaulospora sp., apresentando maior acúmulo de $\mathrm{N}$ foliar, em relação às mudas dos demais clones. Quando inoculadas pelo fungo $E$. infrequens, mudas do clone 2361 apresentaram maior conteúdo de $\mathrm{N}$, na parte aérea, diferindo, significativamente, das mudas dos clones 1250, 0321, 5204 e 5341 .

Não houve diferença significativa entre o teor de $\mathrm{P}$ da parte aérea das mudas do clone 1250 inoculadas com as espécies fúngicas e das não inoculadas (controle). A inoculação com o fungo G. etunicatum promoveu incremento de $46,4 \%$, no conteúdo de $\mathrm{P}$, na parte aérea do clone 0321 . Foram observados incrementos de $94,1 \%, 68,7 \%$ e $45,2 \%$, respectivamente, no conteúdo de $\mathrm{P}$, na parte aérea 
Tabela 3. Conteúdo de N, P e K, na parte aérea das mudas de eucalipto inoculadas com fungos micorrízicos arbusculares (Cruz das Almas, BA, 2011).

\begin{tabular}{|c|c|c|c|c|c|}
\hline \multirow{2}{*}{ Espécie fúngica } & \multicolumn{5}{|c|}{ Clones de Eucaliptus grandis x Eucaliptus urophylla } \\
\hline & 1250 & 0321 & 2361 & 5204 & 5341 \\
\hline & \multicolumn{5}{|c|}{$N\left(g\right.$ planta $\left.^{-1}\right)$} \\
\hline Glomus etunicatum & $0,017 \mathrm{aA}$ & $0,018 \mathrm{aA}$ & $0,013 \mathrm{cB}$ & $0,012 \mathrm{bB}$ & $0,021 \mathrm{aA}$ \\
\hline Glomus manihots & $0,019 \mathrm{aA}$ & $0,017 \mathrm{aA}$ & $0,015 \mathrm{cB}$ & $0,012 \mathrm{bB}$ & $0,017 \mathrm{bA}$ \\
\hline Acaulospora sp. & $0,019 \mathrm{aB}$ & $0,017 \mathrm{aB}$ & $0,020 \mathrm{bB}$ & $0,011 \mathrm{bC}$ & $0,024 \mathrm{aA}$ \\
\hline Entrophosphora infrequens & $0,022 \mathrm{aC}$ & $0,015 \mathrm{aB}$ & $0,027 \mathrm{aA}$ & $0,016 \mathrm{aB}$ & $0,017 \mathrm{bC}$ \\
\hline Controle & $0,016 \mathrm{aA}$ & $0,018 \mathrm{aA}$ & $0,013 \mathrm{cA}$ & $0,008 \mathrm{bB}$ & $0,015 \mathrm{bA}$ \\
\hline \multirow[t]{2}{*}{$\mathrm{CV}(\%)$} & \multicolumn{5}{|c|}{18,38} \\
\hline & \multicolumn{5}{|c|}{$P\left(g\right.$ planta $\left.^{-1}\right)$} \\
\hline Glomus etunicatum & $0,0034 \mathrm{aA}$ & $0,0041 \mathrm{aA}$ & $0,0029 \mathrm{aB}$ & $0,0027 \mathrm{aB}$ & $0,0038 \mathrm{aA}$ \\
\hline Glomus manihots & $0,0027 \mathrm{aA}$ & $0,0033 \mathrm{bA}$ & $0,0024 \mathrm{aA}$ & $0,0024 \mathrm{aA}$ & $0,0028 \mathrm{bA}$ \\
\hline Acaulospora sp. & $0,0012 \mathrm{bB}$ & $0,0012 \mathrm{cB}$ & $0,0006 \mathrm{cC}$ & $0,0015 \mathrm{bB}$ & $0,0022 \mathrm{bA}$ \\
\hline Entrophosphora infrequens & $0,0023 \mathrm{aB}$ & $0,0025 \mathrm{bB}$ & $0,0033 \mathrm{aB}$ & $0,0027 \mathrm{aB}$ & $0,0045 \mathrm{aA}$ \\
\hline Controle & $0,0026 \mathrm{aA}$ & $0,0028 \mathrm{bA}$ & $0,0017 \mathrm{bB}$ & $0,0016 \mathrm{bB}$ & $0,0031 \mathrm{bA}$ \\
\hline \multirow[t]{2}{*}{$\mathrm{CV}(\%)$} & \multicolumn{5}{|c|}{22,93} \\
\hline & \multicolumn{5}{|c|}{$K\left(g\right.$ planta $\left.^{-1}\right)$} \\
\hline Glomus etunicatum & $0,050 \mathrm{aA}$ & $0,049 \mathrm{aA}$ & $0,039 \mathrm{bB}$ & $0,031 \mathrm{aB}$ & $0,052 \mathrm{bA}$ \\
\hline Glomus manihots & $0,047 \mathrm{aA}$ & $0,043 \mathrm{bA}$ & $0,041 \mathrm{bA}$ & $0,029 \mathrm{aC}$ & $0,060 \mathrm{aA}$ \\
\hline Acaulospora sp. & $0,042 \mathrm{aC}$ & $0,055 \mathrm{aA}$ & $0,047 \mathrm{bB}$ & $0,033 \mathrm{cD}$ & $0,059 \mathrm{aA}$ \\
\hline Entrophosphora infrequens & $0,034 \mathrm{bC}$ & $0,046 \mathrm{aB}$ & $0,061 \mathrm{aA}$ & $0,036 \mathrm{aC}$ & $0,045 \mathrm{bB}$ \\
\hline Controle & $0,035 \mathrm{bB}$ & $0,038 \mathrm{bB}$ & $0,030 \mathrm{cC}$ & $0,021 \mathrm{bD}$ & $0,047 \mathrm{bA}$ \\
\hline $\mathrm{CV}(\%)$ & \multicolumn{5}{|c|}{14,60} \\
\hline
\end{tabular}

dos clones 2361, 5204 e 5341, proporcionados pelo fungo $E$. infrequens.

Quando avaliado o efeito da inoculação de cada espécie fúngica, entre os clones de eucalipto, foi possível perceber que mudas dos clones $1250,0321 \mathrm{e}$ 5341 foram as que apresentaram maior acúmulo de $\mathrm{P}$, na parte aérea, em relação às mudas dos clones 2361 e 5204, quando inoculadas pelo fungo G. etunicatum. Mudas do clone 5341 foram as que melhor responderam à inoculação dos fungos Acaulospora sp. e E. infrequens, apresentando maior conteúdo de $\mathrm{P}$, em relação às mudas dos demais clones.

Com exceção do fungo E. infrequens, as demais espécies fúngicas promoveram aumento no conteúdo de $\mathrm{K}$, na parte aérea do clone 1250 . Com relação ao clone 0321, observou-se que as mudas inoculadas pelo fungo $G$. manihots não diferiram, estatisticamente, das mudas não inoculadas (controle), entretanto, as demais espécies fúngicas promoveram incremento de até $44,7 \%$, no conteúdo de $\mathrm{K}$, na parte aérea. A inoculação com o fungo $E$. infrequens promoveu incremento de $103,3 \%$, no conteúdo de $\mathrm{K}$, na parte aérea do clone 2361. No clone 5204, a inoculação com o fungo E. infrequens também promoveu aumento do conteúdo de $\mathrm{K}(71,4 \%)$, contudo, este não diferiu, significativamente, dos fungos G. etunicatum e G. manihots. Em mudas do clone 5341, os fungos G. manihots e Acaulospora sp. promoveram incrementos de $27,6 \%$ e $25,5 \%$, no conteúdo de $\mathrm{K}$, na parte aérea.

De modo geral, a inoculação das espécies fúngicas estimulou o crescimento e promoveu melhoria nutricional das mudas de eucalipto, em comparação às mudas não inoculadas. Os melhores resultados foram registrados nas mudas do clone 2361, quando colonizadas pelo fungo E. infrequens. A inoculação de Glomus clarum e Gigaspora margarita promoveu incremento significativo no acúmulo de nutrientes e no crescimento de mudas de peroba rosa, sendo consideradas, por Marchineski et al. (2009), espécies com grande potencial para a produção de mudas desta espécie florestal. Mudas de pinhão manso inoculadas com G. clarum e adubadas com doses crescentes de composto orgânico apresentaram incrementos de até $93 \%$ e $50 \%$, respectivamente, nos teores de $\mathrm{P}$ e $\mathrm{N}$ da parte aérea (Schiavo et al. 2010b).

Os fungos micorrízicos promovem melhoria no estado nutricional das plantas, em virtude de as 
hifas fúngicas possuírem alta capacidade de absorção de nutrientes e maior facilidade de acesso aos microporos que às raízes, e, portanto, exploram, de maneira mais eficiente, o solo. Além disto, as hifas produzem e exsudam compostos orgânicos que atuam na solubilização de fosfatos, promovendo a disponibilização de $\mathrm{P}$ e outros nutrientes, para as plantas.

Outro aspecto muito importante pôde ser observado por meio dos resultados apresentados no tratamento controle, ou seja, quando as mudas não foram inoculadas com os FMA. Foi possível perceber, por meio dos parâmetros de crescimento (altura das plantas, diâmetro do caule, produção de biomassa seca na parte aérea e raízes) e de nutrição (conteúdo de N, P e K, na parte aérea), que, na maioria das situações, houve diferença significativa entre os clones, o que significa dizer que, independentemente da simbiose micorrízica, existe, também, influência do potencial genético dos clones sobre o crescimento e a eficiência nutricional (Wadt et al. 1999, Lima et al. 2005, Pinto et al. 2011).

Raízes dos clones de eucalipto do tratamento controle apresentaram-se isentas de colonização micorrízica. Nos tratamentos em que houve inoculação das espécies fúngicas, a colonização radicular variou entre $13,5 \%$ e $49,5 \%$ (Tabela 4 ).

O eucalipto é uma espécie florestal muito susceptível à simbiose micorrízica. Campos et al. (2011), realizando estudo sobre a condição micorrízica, em plantios de eucalipto localizados na região leste de Minas Gerais, verificaram que a taxa de colonização das plantas pelos FMA foi de até $62,1 \%$. Em plantios de eucalipto localizados no litoral norte da Bahia, Araújo et al. (2004) verificaram que, em algumas áreas, as plantas apresentavam percentagem de colonização micorrízica acima de $90 \%$.

Além do eucalipto, estudos já demonstraram que outras espécies florestais apresentam alta dependência da simbiose micorrízica. Rocha et al. (2006) verificaram colonização micorrízica em raízes de cedro, mesmo após a aplicação de doses crescentes de $\mathrm{P}$ ao solo $\left(960 \mathrm{mg} \mathrm{kg}^{-1}\right)$ em que foram cultivadas as plantas. Mudas de angico apresentaram alta taxa de colonização $(66,5 \%)$, pelos fungos G. etunicatum e Gigaspora margarita (Sugai et al. 2011). Schiavo et al. (2010b) constataram que mudas de pinhão manso apresentaram taxa de colonização radicular pelos FMA de até 90\%, em condições de elevada fertilidade do solo, sugerindo alta dependência micorrízica desta espécie.

Esses resultados ressaltam a importância da utilização da tecnologia de inoculação dos FMA, em espécies florestais para reflorestamento, que, na maioria das vezes, ocorrem em solos de baixa fertilidade e com reduzido potencial de inóculo micorrízico nativo.

Com relação ao presente estudo, observou-se que o fungo G. etunicatum apresentou boa capacidade de colonização, nas raízes do clone 1250 (45,1\%), em relação às demais espécies fúngicas, que não diferiram, estatisticamente, entre si. No clone 0321 , maior percentagem de colonização radicular foi registrada pelo fungo Acaulospora sp. (49,5\%). Não houve diferença significativa entre as espécies fúngicas, com relação à colonização das raízes, nas mudas do clone 2361. Foi registrada baixa taxa de colonização radicular pelo fungo Acaulospora sp., nas raízes dos clones 5204 (18,5\%) e 5341 (14,0\%), conforme escala proposta por Carneiro et al. (1998).

Tabela 4. Índices de colonização micorrízica, compatibilidade absoluta, compatibilidade funcional e compatibilidade da planta (ICP), determinados para mudas de diferentes clones de eucalipto (Cruz das Almas, BA, 2011).

\begin{tabular}{|c|c|c|c|c|c|c|c|}
\hline \multirow{4}{*}{ Espécie fúngica } & \multicolumn{5}{|c|}{ Clones de Eucaliptus grandis x Eucaliptus urophylla } & \multirow{2}{*}{\multicolumn{2}{|c|}{$\begin{array}{c}\text { Índice de } \\
\text { compatibilidade }\end{array}$}} \\
\hline & 1250 & 0321 & 2361 & 5204 & 5341 & & \\
\hline & \multicolumn{5}{|c|}{ Índice de colonização micorrízica } & Absoluta & Funcional \\
\hline & \multicolumn{5}{|c|}{$\%$ \%- } & & + \\
\hline G. etunicatum & $45,1 \mathrm{aA}$ & $31,5 \mathrm{bB}$ & $27,0 \mathrm{aB}$ & $30,5 \mathrm{aB}$ & $13,5 \mathrm{bC}$ & 100 & 80 \\
\hline G. manihots & $24,5 \mathrm{bA}$ & $33,0 \mathrm{bA}$ & $31,0 \mathrm{aA}$ & $28,5 \mathrm{aA}$ & $23,5 \mathrm{aA}$ & 100 & 100 \\
\hline Acaulospora sp. & $33,0 \mathrm{bB}$ & $49,5 \mathrm{aA}$ & $26,9 \mathrm{aC}$ & $18,5 \mathrm{bD}$ & $14,0 \mathrm{bD}$ & 100 & 60 \\
\hline E. infrequens & $30,5 \mathrm{bA}$ & $36,5 \mathrm{bA}$ & $30,5 \mathrm{aA}$ & $28,0 \mathrm{aA}$ & $25,9 \mathrm{aA}$ & 100 & 100 \\
\hline Média & 33,3 & 37,6 & 28,8 & 26,4 & 19,2 & - & - \\
\hline Índice de compatibilidade da planta (\%) & 25,0 & 25,0 & 50,0 & 75,0 & 50,0 & - & - \\
\hline
\end{tabular}


Os resultados demonstraram que a taxa de colonização pela mesma espécie fúngica variou entre os clones de eucalipto. Fatores edafoclimáticos e aspectos genéticos da relação fungo-planta influenciam na taxa de colonização e na resposta à micorrização.

Um aspecto interessante a ser considerado é que a percentagem de colonização micorrízica nem sempre é uma característica segura, para se definir o efeito que a espécie fúngica exerce sobre o crescimento e nutrição da planta hospedeira (Schiavo et al. 2010a). Muitas vezes, as espécies de FMA possuem mecanismos evoluídos em infectividade, contudo, não se apresentam especializadas em fornecer benefício para a planta, ou seja, são ineficientes nas trocas, não favorecendo o crescimento e nutrição da planta hospedeira (Sena et al. 2004).

Foi possível observar, no presente trabalho, que, em muitas situações, as espécies fúngicas que apresentaram maior taxa de colonização não promoveram incremento significativo no crescimento e nutrição dos clones, em comparação às mudas controle (Tabelas 2 e 3).

As espécies fúngicas apresentaram índice de compatibilidade absoluta (ICA) de 100\%, indicando alta capacidade destes fungos em colonizar os diferentes clones de eucalipto, independentemente da extensão da colonização. Contudo, o índice de compatibilidade funcional (ICF) de $100 \%$ demonstrou que os fungos G. manihots e E. infrequens apresentaram maior compatibilidade com os clones avaliados, quando comparados com os fungos G. etunicatum (80\%) e Acaulospora sp. (60\%).

O clone 5204 foi o que apresentou maior compatibilidade, estabelecendo associação com $75 \%$ das espécies fúngicas, seguido pelos clones 2361 e 5341, ambos com ICP de 50\%. Os clones 1250 e 0321 apresentaram ICP de $25 \%$, sugerindo que estes são mais restritivos. Segundo Pouyu-Rojas et al. (2006), plantas com maiores ICp apresentam maior chance de serem colonizadas por FMA nativos do solo, ao contrário daquelas com baixo ICp, que são mais seletivas.

\section{CONCLUSÕES}

1. A simbiose micorrízica favoreceu o crescimento de plantas e a absorção dos nutrientes $\mathrm{N}, \mathrm{P}$ e K, em mudas de eucalipto.

2. Os fungos Glomus manihots e Entrophospora infrequens apresentaram alto índice de compa- tibilidade funcional com os clones de eucalipto testados.

\section{REFERÊNCIAS}

ARAÚJO, C. V. M. et al. Micorriza arbuscular em plantações de Eucalyptus cloeziana F. Muell no litoral norte da Bahia, Brasil. Acta Botanica Brasilica, Feira de Santana, v. 18, n. 3, p. 513-520, 2004.

BEVER, J. D. Host-especificity of AM fungal population growth rates can generate feedback on plant growth. Plant and Soil, Bethlehem, v. 244, n. 1-2, p. 281-290, 2002.

CAMPOS, D. T. S. et al. Colonização micorrízica em plantios de eucalipto. Revista Árvore, Viçosa, v. 35, n. 5, p. 965-974, 2011.

CARNEIRO, M. A. C. et al. Micorriza arbuscular em espécies arbóreas e arbustivas nativas de ocorrência no sudeste do Brasil. Cerne, Lavras, v. 4, n. 1, p. 129-145, 1998.

CARNEIRO, M. A. C.; SIQUEIRA, J. O.; DAVIDE, A. D. Fósforo e inoculação com fungos micorrízicos aubusculares no estabelecimento de mudas de embaúba (Cecropia pachystachua Trec). Pesquisa Agropecuária Tropical, Goiânia, v. 34, n. 3, p. 199-125, 2004.

CAVALCANTE, U. M. T. et al. Mycorrhizal dependency of passion fruit (Passiflora edulis f. flavicarpa). Fruits, Cambridge, v. 56, n. 5, p. 317-324, 2001.

GOMES, J. M. et al. Efeito de diferentes substratos na produção de mudas de Eucalyptus grandis W. Hill ex Maiden, em "Win-Strip". Revista Árvore, Viçosa, v. 15, n. 1, p. 35-42, 1991.

HERRMAN, S.; OELMMULLER, R.; BUSCOT, F. Manipulation of the onset of ectomycorrhyza formation by indole-3-acetic acid, activated charcoal or relative humidity in the association between oak microcuttings and Piloderma croceum influence on plant development and photosynthesis. Journal of Plant Physiology, Irvine, v. 161, n. 5, p. 509-517, 2004.

KOSKE, R. E.; GEMMA, J. N. A modified procedure for staining roots to detect mycorrhizas. Mycological Research, Cambridge, v. 48, n. 4, p. 486-488, 1989.

LIMA, A. M. N. et al. Cinética de absorção e eficiência nutricional de $\mathrm{K}, \mathrm{Ca}$ e $\mathrm{Mg}$ em plantas jovens de quatro clones de eucalipto. Revista Brasileira de Ciência do Solo, Viçosa, v. 29, n. 5, p. 903-909, 2005.

LOPES, J. L. W. Qualidade de mudas clonais do híbrido de Eucalyptus grandis vs. Eucalyptus urophylla submetidas a diferentes regimes hídricos. 2008. $171 \mathrm{f}$. Tese (Doutorado em Agronomia - Irrigação e Drenagem) - Universidade 
Estadual Paulista "Júlio de Mesquita Filho", Botucatu, 2008.

MACHINESKI, O. et al. Crescimento de mudas de peroba rosa em resposta à inoculação com fungos micorrízicos arbusculares. Ciência Rural, Santa Maria, v. 39, n. 2, p. 567-570, 2009.

MELLO, A. H. et al. Fungos arbusculares e ectomicorrízicos em áreas de eucalipto e de campo nativo em solo arenoso. Ciência Florestal, Santa Maria, v. 16, n. 3, p. 293-301, 2006.

MORATELLI, E. M. et al. Efeito da disponibilidade de água e de luz na colonização micorrízica e no crescimento de Tabebuia avellanedae Lorentz ex Griseb. (Bignoniaceae). Revista Árvore, Viçosa, v. 31, n. 3, p. 555566, 2007.

PINTO, S. I. C. et al. Eficiência nutricional de clones de eucalipto na fase de mudas cultivados em solução nutritiva. Revista Brasileira de Ciência do Solo, Viçosa, v. 35, n. 4, p. 523-533, 2011.

POUYU-ROJAS, E.; SIQUEIRA, J. O.; SANTOS, J. G. D. Compatibilidade simbiótica de fungos micorrízicos arbusculares com espécies arbóreas tropicais. Revista Brasileira Ciência do Solo, Viçosa, v. 30, n. 3, p. 413424, 2006.

ROCHA, F. S. et al. Dependência e resposta de mudas de cedro a fungos micorrízicos arbusculares. Pesquisa Agropecuária Brasileira, Brasília, DF, v. 41, n. 1, p. 7784, 2006.

SAGGIN JÚNIOR, O. J.; SIQUEIRA, J. O. Avaliação da eficiência simbiótica de fungos endomicorrízicos para o cafeeiro. Revista Brasileira de Ciência do Solo, Viçosa, v. 19, n. 2, p. 221-228, 1995.

SCHIAVO, J. A.; MARTINS, A. M.; RODRIGUES, L. A. Crescimento de mudas de Acacia mangium, Sesbania virgata e Eucalyptus camaldulensis, inoculadas com fungos micorrízicos, em casa-de-vegetação e em cava-deextração de argila. Acta Scientiarum Agronomy, Maringá, v. 32, n. 1, p. 171-178, 2010a.

SCHIAVO, J. A. et al. Composto orgânico e inoculação micorrízica na produção de mudas de pinhão manso. Pesquisa Agropecuária Tropical, Goiânia, v. 40, n. 3, p. 322-329, 2010.

SCHÜßLER, A.; SCHWARZOTT, D.; WALKER, C. A new fungal phylum, the Glomeromycota: phylogeny and evolution. Mycological Research, Cambridge, v. 105, n. 12, p. 1413-1421, 2001.

SENA, J. O. A.; LABATE, C. A.; CARDOSO, E. J. B. N. Caracterização fisiológica da redução de crescimento de mudas de citrus micorrizadas em altas doses de fósforo. Revista Brasileira de Ciência do Solo, Viçosa, v. 28, n. 5 , p. 827-832, 2004.

SUGAI, M. A. A.; COLLIER, L. S.; SAGGIN JÚNIOR, O. J. Inoculação micorrízica no crescimento de mudas de angico em solo de Cerrado. Bragantia, Campinas, v. 70, n. 2, p. 416-423, 2011.

SOUSA, C. S. et al. Fungos micorrízicos arbusculares no controle de Meloidogyne incognita em mudas de tomateiro. Revista Caatinga, Mossoró, v. 23, n. 1, p. 1520, 2010.

THOMAS, R. L.; SHEARD, R. W.; MOYER, J. R. Comparison of conventional and automated procedure for nitrogen, phosphorus and potassium analysis of plant material using single digest. Agronomy Journal, Madison, v. 59, n. 1, p. 240-243, 1967.

WADT, P. G. S. et al. Variações no estado nutricional de eucaliptos por influência do material genético e da idade da árvore. Pesquisa Agropecuária Brasileira, Brasília, DF, v. 34, n. 10, p. 1797-1803, 1999. 